Teorema

Vol. XVI/2, 1997, pp. 61-76

\title{
Meaning, Truth and Phenomenology
}

\author{
Mark Bevir
}

\section{RESUMEN}

Este artículo examina las tesis de Derrida a través de una consideración de sus escritos sobre Saussure y Husserl. Derrida tiene razón al insistir, siguiendo a Saassure, en una teoría relacional del significado: las palabras no tienen una correspondencia biunívoca con sus referentes. Sin embargo, está equivocado al insistir en una teoría del significado puramente diferencial: las palabras pueden referirse a la realidad dentro del contexto de un cuerpo de conocimiento. Del mismo modo, Derrida tiene razón al rechazar la idea husserliana de presencia: no hay verdad alguna que sea dada, simplemente, a la conciencia. Sin embargo, está equivocado al rechazar la idea de conocimiento objetivo: podemos defender una noción de conocimiento objetivo formulada en términos de una comparación de cuerpos rivales de teorías. Este artículo concluye considerando las implicaciones de los argumentos precedentes para la empresa de la fenomenología.

\section{ABSTRACT}

This essay approaches Derrida through a consideration of his writings on Saussure and Husserl. Derrida is right to insist, following Saussure, on a relational theory of meaning: words do not have a one to one correspondence with their referents. However, he is wrong to insist on a purely differential theory of meaning: words can refer to reality within the context of a body of knowledge. Similarly, Derrida is right to reject Husserl's idea of presence: no truths are simply given to consciousness. However he is wrong to reject the very idea of objective knowledge: we can defend a notion of objective knowledge couched in terms of a comparison of rival bodies of theories. This paper concludes by considering the implications of the preceding arguments for the enterprise of phenomenology.

\section{INTRODUCTION}

Jacques Derrida rejects our philosophical tradition as logocentric - a discourse of reason centred on a misplaced faith in stable meanings and objective truths. According to Derrida, neither meanings nor truths are simply present to consciousness. Rather, all concepts are metaphors that do not refer to a fixed presence, and all consciousness deploys such metaphors, so we cannot have access to brute facts. Derrida's rejection of logocentrism precludes his offering a set of doctrines defended by using the very discourse 
cludes his offering a set of doctrines defended by using the very discourse of reason he rejects. Instead he conveys his views through deconstructive readings of other philosophers - his view of meaning through a reading of Ferdinand de Saussure, and his attack on truth through one of Edmund Husserl. I will approach Derrida's critique of logocentrism, therefore, through his writings on Saussure and Husserl. I hope to show that aspects of his criticisms of them are valid, in that he does pose problems for some theories of meaning and truth. In addition, however, I hope to show that his criticisms of them cannot sustain his complete rejection of meaning and truth. Provided we conceptualise meaning and truth in the right way, we can avoid the problems Derrida raises.

\section{SAUSSURE AND MEANING}

When Derrida famously proclaims "there is nothing outside of the text," he is arguing there is nothing outside the text for us; but then, of course, to say there is nothing outside the text for us is in effect to say there is nothing outside the text [Derrida (1977), p. 163]. According to Derrida, we cannot have knowledge of anything beyond language because language cannot represent the world. Words do not have stable meanings: they do not refer to fixed concepts so they cannot embody knowledge of the world. Derrida, therefore, problematises the question of meaning in a way that promotes an anti-realist scepticism. He argues that signification always entails an element of diffe[/]rance. Whenever we tie a signifier to a signified, the nature of both signifier and signified depends on something other than itself, an absent. We cannot say what a signifier refers to without evoking an absent, and once we evoke an absent, we cannot say what it refers to without evoking another absent, and so on. As Derrida explains:

It is because of diffe[/] rance that the movement of signification is possible only if each so-called 'present' element, each element appearing on the scene of presence, is related to something other than itself, thereby keeping within itself the mark of the past element, and already letting itself be vitiated by the mark of its relation to the future element, this trace being related no less to what is called the future than to what is called the past, and constituting the present by means of this very relation to what it is not [Derrida (1982), p. 13].

Derrida rejects stable meanings on the grounds that signifiers and signifieds depend on what they are not. This differential nature of the sign destabilises meaning in a way that precludes our breaking out of an endless play of signifiers. 
Derrida adopts a differential view of the sign in his reading of Saussure. According to Saussure, language is an abstract system of signs, where a sign conjoins a signifier, or form, with a signified, or concept. The sign "pet", for instance, consists of the signifier made up of the letters "p", "e", and " $\mathrm{t}$ " together with the signified "a tamed animal kept as a favourite". Saussure argues that signs are arbitrary and differential in two respects. First, signifiers are purely differential because their link to a particular signified is arbitrary. There is no reason why a given set of phonemes should convey a certain concept: for example, we could use the signifier "tet" just as easily as "pet" to denote "a tamed animal kept as a favourite". This arbitrary feature of the sign implies that signifiers are indeed differential entities defined solely by their difference from one another; after all, although a signifier need not be linked to any particular signified, it must differ from other signifiers any set of phonemes we use to denote "a tamed animal kept as a favourite" must differ from those we use to convey other concepts. Second, Saussure suggests that signifieds are as arbitrary and differential as signifiers. A common way of explicating this idea is to instance colour concepts, though Saussure himself only uses phonetic examples because he thinks semantic ones would be too complex [Saussure (1966), pp. 83-7]. Imagine we try to teach pupils the concept red by pointing to red things and saying "red". If we show them an orange and ask if it is red, they will not know. We cannot explicate a colour concept merely by instancing examples of it. Why is this? According to Saussure, we experience reality as an undifferentiated continuum - our reality is a jumble of images all of which flow into one another. We experience colour, for example, as a continuum moving from what we call red to what we call yellow and so on. Moreover, because our images of reality form an undifferentiated continuum, we have no reason to divide them up using one set of signifieds rather than another. We could conceptualise colour, for example, using a set of signifieds such as: $\mathrm{X}$ containing what we conceive of as red, orange and about half of yellow, $\mathrm{Y}$ containing the other half of yellow and a tiny fraction of green, $\mathrm{Z}$ containing most of the rest of green, and so on. Our signifieds, therefore, provide just one possible way of dividing up our flow of impressions: they are not a naturally determined set, but rather an arbitrary way of dividing up the jumble of images constitutive of our experiences. However, the argument continues, we could teach our pupils the meaning of red by introducing them to our colour concepts as a set. If we did so, they would know whether an object was red, orange, yellow, green, blue, or whatever. It appears, therefore, that colour concepts are differential since we make sense of red by knowing it is not-orange, not-yellow, not-green, not-blue, and so on. Certainly Saussure concludes that because signifieds are arbitrary, they must be differential - "the conceptual side of value [a unit in language] is made up 
solely of relations and differences with respect to the other terms of language" [Saussure (1966), p. 117].

When Derrida reads Saussure, he takes the arbitrary and differential nature of the sign for granted so as to question the idea of a stable link between signifier and signified, and thus Saussure's phonocentrism, his privileging of speech over writing [Derrida (1977), pp. 27-73]. For Derrida, speech represents stable meanings and writing represents the undermining of stable meanings; a faith in speech stands for a belief in our ability to grasp meanings clearly - speakers know what they mean; a fear of writing stands for a neglect of all that unsettles the link between a statement and its meaning - we wonder what written texts mean. Saussure constantly treats writing as a lesser form of speech by, for example, using phonology as a model for linguistics, and describing phonetic scripts as superior to alternatives like hieroglyphs. According to Derrida, Saussure's phonocentrism entails a neglect of the disruptive effects of writing.

Saussure presents the sign as a fluid construct except when he introduces a stable link between signifier and signified as exemplified in speech. Derrida argues that the existence of this stable link is brought into question by passages in Saussure's own text, passages that exhibit the logical course of his grasp of the differential nature of the sign. Saussure's differential view of the sign makes language (langue) essential for the appearance of speech (parole). Here parole occurs only in a system of differences devoid of positive terms, and such a system resembles the traditional view of writing as the sign of a sign. Indeed Saussure explicitly evokes this resemblance when he uses writing as a metaphor to explicate the nature of langue. Thus, although he says he wants to exclude writing from his linguistics, his own text shows he has to use writing as a metaphor to sustain his argument; his own text shows the centrality of writing and thereby undermines his explicit belief in a stable relationship between signifier and signified. The ubiquity of writing implies all meaning is problematic. As Derrida explains, within every system, there comes a point "where the signifier can no longer be replaced by its signified, so that in consequence no signifier can be replaced, purely and simply" [Derrida (1977), p. 266]. Because signifiers are not tied clearly to signifieds, every use of a signifier resembles writing; every use of a signifier raises as a genuine problem the question of what it refers to. The use of signifiers always corresponds to writing, understood as an opacity that divorces expression from meaning. The use of signifiers can never correspond to the ideal of speech understood as a transparent medium for consciousness. Because we cannot reduce a signifier to a corresponding signified, any attempt to say what a signifier signifies must leave something or other out. There are no stable meanings.

Perhaps Derrida is right; perhaps the differential nature of the sign implies signifiers are not bound to fixed signifieds so there are no stable meanings just an endless play of signifiers. However, even if he is right, his 
conclusion clearly remains parasitic on Saussure's differential view of the sign. Derrida takes as given a view of the sign which is, I think, mistaken. Saussure adopts a differential view of the signified as a consequence of his postulating langue as the proper object of a science of linguistics. Because he defines langue as a self-contained system, he cannot identify its individual parts by their relationship to things beyond that system. Thus, his account of the signified rests not on a philosophical argument about how things are, but on a methodological gesture designed to establish linguistics as a science ${ }^{1}$. The argument for a differential theory of meaning rests solely, therefore, on the evidence provided by examples such as colour concepts. This evidence, however, only shows that some concepts form a continuum that could be divided up in another way. It only shows that some concepts are differential: they refer to a continuum, so we know what part of the continuum one refers to if we know what part of the continuum the others do not refer to. It does not show that all concepts are purely differential: not all concepts need be part of a continuum, and, what is more, we might know what one that is part of a continuum refers to even if we do not know what the relevant others refer to.

Derrida, albeit implicitly, makes an unwarranted leap. He moves from showing some signifieds are differential to the conclusion that all signifieds are purely differential. The illegitimate nature of this move appears in two failings in his purely differential theory of meaning. The first is that even concepts forming a continuum can be defined positively as well as differentially. That we can define colour concepts negatively as not one another does not establish that we cannot define them positively in terms of their referents. Consider again that we want to teach the meaning of red to our pupils. Imagine we tell them an object is red if the light it reflects lies somewhere beyond a specified point on the spectrum. Also imagine that we give them an instrument with which to measure the nature of the light given off by any object. Under these circumstances, they could identify red objects without any problem; they could fix the meaning of red by knowing what objects red refers to, and they could do so even if they did not know the meaning of other colour concepts. Clearly, therefore, we do not have to define red differentially. We can define it positively as the colour seen at such and such a band of the spectrum. Red is a relational concept: we fix its meaning in relation to other signifieds that provide us with a theory of the nature of colour. Nonetheless, red is not a purely differential concept: it is not composed solely of the contrast between it and other concepts. Of course, we still can say that red is the part of the spectrum that is not-blue, not-green, and so on. We can do so, however, because our theory of colour implies colour concepts form a continuous spectrum because anything giving off light gives off colour and light forms a continuous spectrum. It is, therefore, a fact about our world that light forms a continuous spectrum - not a fact about meaning — that we define 
signifieds as different from one another - that enables us to equate red with not-blue, not-green, and so on.

The second failing of Derrida's purely differential theory of meaning is that most concepts do not form a continuum so we can define them only in positive terms. Consider the signified malaria. No doubt we cannot teach someone what we mean by malaria solely by pointing to examples and saying "malaria". But this shows only that the meaning of malaria depends on a theoretical understanding of the world: malaria is a relational concept. It does not show that the meaning of malaria derives from its not being various other concepts: malaria is not a purely differential concept. Indeed, we can define malaria positively as, say, a fever caused by the presence in the body of the protozoan parasite of genus Plasmodium. To do so we need only to accept a theory about the cause of certain physical symptoms. Once again we can bind a signified to its referent in the context of theories composed of other signifieds. What is more, this time the relevant theories actually preclude a differential definition of malaria akin to that we can give of red. We could only say that malaria means something like "not the absence of a certain type of parasite". Malaria is not a differential signified, just a relational one.

Derrida's purely differential theory of meaning rests on a false dichotomy. He assumes that because individual signifieds do not have a context-independent link to their referents, we can therefore identify them only negatively as different from each other. Actually, however, there is another alternative: we could identify them positively in terms of an external reality, where the way we understand this reality presupposes the applicability of various theories. When Derrida says "the absence of the transcendental signified extends the domain and the play of signification infinitely," he ignores the possibility of our theories providing a way of ending such play without appealing to a transcendental signified [Derrida (1978b), p. 280]. There is no reason why we should assume that the absence of a one to one correspondence between signifieds and their referents entails the absence of any correspondence whatsoever. That a signified cannot refer to reality in isolation does not imply that it cannot refer to reality within a context composed of other relevant signifieds. On the contrary, the positive relations between signifieds enable them to refer to reality. Derrida errs when he says "language is entirely intertextual - words refer to one another in wholly contingent manners without touching any trans-linguistic reality" [Derrida (1977), p. 50].

Derrida's critique of stable meanings might seem to rest not simply on his analysis of the signified, but also on his practice of deconstruction, his games with language, and so on. In fact, however, the procedures Derrida uses to problematise meaning all fail along with his purely differential theory of meaning. Derrida deploys deconstruction, metaphors, and the like in order to show how arguments for stable meanings undermine themselves. 
Crucially, an argument might undermine itself in two different ways. First, there might be a logical contradiction in the intellectual content of an argument. Such contradictions trouble all philosophers. Second, there might be a contradiction between the intellectual content of an argument' and the way it is made. This is the sort of contradiction upon which Derrida alights when he deconstructs texts. Yet, his justification for worrying about this second sort of contradiction depends entirely on his purely differential theory of meaning. Only if there are no stable signifieds will we treat signifieds as akin to signifiers: only if there are no stable meanings will we treat the intellectual content of an argument as akin to the way it is made. If there are stable meanings, we will consider the validity of the intellectual content of an argument independently of the manner of its performance. Thus, because signifieds are not differential, Derrida cannot problematise meaning simply by pointing to a contradiction between what a text says and how it says it. (He could only problematise meaning by pointing to logical contradictions in all arguments for stable meanings, and this he does not do.)

Consider Derrida's reading of Saussure. On the one hand, Derrida points to a contradiction between the content and performance of Saussure's Course in General Linguistics. Derrida argues that Saussure undermines his own argument for the priority of speech over writing because he explains the nature of speech by reference to writing. But there is no problem here. Saussure thinks speech is prior to writing, but because the latter is more familiar to us he finds it useful to explain the nature of the former by reference to the latter. We can use one to explain the other without thereby being committed to regarding the latter as prior to the former. On the other hand, Derrida points to a contradiction in the content of Saussure's ideas. Derrida argues that Saussure's doctrine of the arbitrary nature of the sign undermines Saussure's belief in the stable link between signifiers and signifieds. If this is so, it is a logical contradiction, so Saussure's attempt to fix this link fails. Nonetheless, the failure of Saussure's attempt to bind signifiers to signifieds would not entail the failure of all such attempts. On the contrary, my relational theory of meaning allows us to bind signifiers to signifieds within a given theoretical context. There are stable meanings; it is simply that they are, in part, products of our theories.

\section{HUSSERL AND TRUTH}

Derrida proceeds from a rejection of stable meanings to a critique of the very idea of truth or objective knowledge. He argues that because we cannot have access to stable meanings, we cannot take anything as a given fact - a simple presence - so we have no foundations on which to ground 
truth-claims. "The dream at the heart of philosophy" is to bring the play of signifiers to an end by appealing to "the assured legibility of the proper" [Derrida (1982), p. 268]. Philosophy exalts a myth of presence: something is given as true to consciousness; it acts as a stable foundation for claims to knowledge. But, Derrida continues, the dream of philosophy can never be realised because there are no stable meanings; nothing is simply given to consciousness; nothing can secure truth-claims.

Derrida's critique of truth appears in is his reading of Husserl. According to Husserl, phenomenology gives us a method for investigating the objects of consciousness [Husserl (1931)]. Consciousness provides the starting point for philosophical inquiry because it is the one thing we cannot deny. When we focus on consciousness, we define its objects as correlative to thought, so we reject the distinction between things we perceive and our perception of them. Philosophers, therefore, investigate things in themselves by bracketing-off all assumptions about a world beyond consciousness. Husserl denies, however, that this phenomenological concentration on the content of consciousness generates only subjective knowledge. He distinguishes between aspects of consciousness that characterise thought as such and ones that are contingent features of the thought of particular individuals. Phenomenology relies on a process of reduction to make this distinction and thereby focus on the objective features of consciousness as such. It gives us access to truths that are simply present to consciousness as such. In The Origin of Geometry, Husserl uses his phenomenological method to analyse geometry [Husserl (1978)]. Although a truth of geometry is realised as true only when it becomes the object of a particular consciousness, it is true $a$ priori in that it is a necessary feature of consciousness as such. A truth of geometry originates in the act of reason that discovers it to be true, and it is recognised as true in each subsequent act of reason that grasps it; but its status as an a priori truth present to consciousness as such remains unaffected by errors in the acts of reason that discover and recognise it to be true.

Against Husserl, Derrida argues that no stable objects are present to consciousness. Any appeal to truths present to consciousness entails an element of subjectivism - a concern with their genesis in the individual mind - from which errors can be excluded only by an appeal to writing. On the one hand, Husserl secures meaning and truth, "the ideal transparency and perfect univocity of language," by appealing to idealised objects that are indefinitely repeatable, that is, a view of the object as a given presence always and everywhere the same [Derrida (1973), p. 52]. On the other hand, he secures the object as a given presence by appealing to writing, which, according to Derrida, undermines the stability of meaning that Husserl wants to establish. Husserl tries to avoid this difficulty by distinguishing expressive from indicative uses of language. When we use language expressively, we 
convey intentional meanings immediately present to consciousness. When we use language indicatively, we merely point indirectly to such meanings. According to Husserl, we can accept writing when it is a transparent medium that facilitates the pure expression and transmission of thought, but not when it acts as an opaque barrier to truths held in, or recognised by, the mind. Derrida, however, objects that writing always has an indicative character. Using Saussure's terminology, he says, "whenever the immediate and full presence of the signified is concealed, the signifier will be of an indicative nature," and, of course, his view of meaning suggests the signified is never fully present but rather always constituted in part by an absence [Derrida (1973), p. 40]. We cannot grasp concepts except through the opacity of the words we use to convey them; writing is always indicative so it cannot secure claims to truth in the way Husserl proposes.

In Derrida's introduction to Husserl's Origin of Geometry, for example, he argues that Husserl can describe geometric truths as present to consciousness only by referring to the writing down of these truths [Derrida (1978a)]. If geometric truths were immediately present to consciousness, we would be unable to allow for the mistakes some individuals make in recognising them. Thus, Husserl has to recognise that objectivity here depends on graphic representations securing the iterability of geometric truths. Husserl has to imply, contrary to his own argument, that only writing gives geometric truths the secure permanence of objective knowledge. Derrida's point here is that although Husserl argues that geometric truths are self-evident to consciousness, he still has to invoke the writing down of these truths in order to secure them as objectively true - his text undermines his explicit argument.

Although Derrida attacks Husserl's idea of a pre-theoretical consciousness by appealing to a differential theory of meaning, a relational theory of meaning, such as the one I have proposed, also implies that we should reject Husserl's metaphysics of presence. A metaphysics of presence postulates a one to one correspondence between concepts and their referents. It implies that signifieds do not need a theoretical context to bind them to their referents. Some signifieds are given to consciousness as brute facts independent of all else. A relational theory of meaning implies that this is not so. If all signifieds are relational, they all require a theoretical context to bind them to their referents. A relational view of meaning implies that the objects which a concept picks out must depend on other concepts, so no concept can pick out objects in the absence of other concepts. The content of consciousness cannot be pre-theoretical. Consider the example of the concept red. Husserl's metaphysics of presence would require some of our concepts to refer to objects in splendid isolation: perhaps we simply see some objects are red, so we conceive of them as red. But I have argued that this is not so: to recognise something as red our pupils need to master other concepts. Red 
is an abstract category that on its own cannot tell us which objects we should and should not place under it. More generally, all signifieds must be relational because when we identify an object as belonging under a given category we classify it in a way that presupposes theories about the world. Theories are implicit in all the objects that appear before consciousness. Nothing is given to us as a simple presence. Crucially, because all signifieds are relational, they can be tied to objects only in a theoretical context, so the truth-value of a statement must depend on our theoretical commitments. Nothing is given to consciousness outside all theoretical contexts. Theoretical assumptions enter into our understanding of every aspect of the world, so we cannot possibly rest our knowledge on pure descriptions of pure experiences empty of all theoretical content. Phenomenologists cannot base objective knowledge on experiences that are simply given to consciousness since even experiences as they are given to consciousness must be experiences of theoretically-constructed objects. Because our world is theoretically-constructed, the dream of philosophy fails, we are left without the possibility of an absolutely certain set of beliefs. We are left, as Derrida puts it, with the fact that our "world is written only in the plural" [Derrida (1982), p. 268].

Derrida is right, therefore, to reject Husserl's concept of objective knowledge as certainty. The relational nature of signifieds, the theory-laden nature of experience, means that no fact is given to us as an indubitable presence. Where Derrida goes astray is in embracing not only an epistemological modesty that recognises the uncertainty of knowledge, but also an antirationalism that seems to deny knowledge any validity whatsoever. Here my relational theory of meaning implies that we can have access to stable objects, where the stability of these objects depends on our theorising; and although the theory-laden nature of consciousness precludes our justifying knowledge in some ways, it does not preclude all such justification.

The theory-laden nature of consciousness implies that there are no given facts and so we cannot compare the content of consciousness with something else, neither the world as it is nor a quasi-Platonic world of ideal forms. Because there are no given facts against which to judge the theoryladen content of consciousness, knowledge cannot be absolutely certain. Firstly, because no single piece of knowledge is given to us as true, the validity of knowledge cannot rest on that of its individual parts. Instead we must justify knowledge as a whole: objectivity must be, at least in the first instance, a property of a body of knowledge. Individual bits of knowledge must be objective by virtue of belonging to an objective body of knowledge. Moreover, because we cannot compare the content of consciousness with something else, we cannot justify a body of knowledge by appealing to an external reality; we cannot say that knowledge is valid because it corre- 
sponds to the world as it is. Instead we must justify knowledge by comparing it with other bodies of theories we might adopt. Any ascription of objectivity must be a result of a comparison between rival bodies of theories. Finally, because knowledge cannot be absolutely certain, any ascription of objectivity must be provisional. When we say a body of knowledge is objective in comparison with its rivals, we do so at a moment in time. Later changes in the rival bodies of knowledge available to us could alter the result of our comparison and thus lead us to renounce the body of knowledge we now take to be true. Because no body of knowledge can stand as a complete account of the world, we must treat ascriptions of objectivity as provisional results of current practices.

My relational theory of meaning implies, therefore, that any acceptable theory of objectivity must proceed by showing how a body of knowledge can meet criteria of comparison in a way that should lead us to accept it provisionally as true. What we take to be objective knowledge must depend not on things present to consciousness, but rather on our activity as theorisers. Firstly, our theories tell us what counts as an exemplary perception of an object. Although exemplary perceptions incorporate theoretical assumptions, they still provide us with shared facts, where these facts are propositions the members of our community accept as true, not truths simply given to consciousness. Our theories assure us of the validity of certain facts, so we can use these facts to justify the rest of our knowledge. Moreover, our theories provide us with criteria of comparison by which to decide between rival accounts of these facts. We can compare competing bodies of knowledge by examining things such as: how well they fit the facts, the number and range of facts they fit, their internal coherence, how many hypotheses they generate, how well the hypotheses they generate fit the facts, and the boldness of the hypotheses they generate. Our theories define criteria that give us a normative standard by which to define a particular body of knowledge as objective. Finally, because the body of knowledge we take to be objective is, therefore, the one that best meets our current criteria, later developments obviously could lead us to renounce it.

Objective knowledge is, therefore, a product of a comparison between rival accounts of agreed facts [Bevir (1994)]. No doubt a comparison between competing bodies of knowledge will not always find one to be notably superior to all others - the value of relativism is to remind us of just this fact. Although we have an objective standpoint from which to reject flatearth theories - a comparison of various theories using established criteria is adequate for this task - there remain several other theories we treat as more or less equally valid - a comparison of them using established criteria does not yield a clear-cut decision. Nonetheless, our inability to decide between various bodies of knowledge does not require us to adopt Derrida's 
anti-rationalism. Not only have we decided between some equally valid theories and other accounts of the world, we also have a rational conclusion to the debate between these equally valid theories - we should say not that the choice between them is an arbitrary one, but rather that an objective standpoint is one that recognises their equal validity.

To avoid Derrida's anti-rationalism, however, we still need a reason to take objective knowledge, as I have defined it, to be true. Here because objective knowledge arises within the context of a social practice, the question of whether or not we should accept it as true depends on the stance we take towards this practice. Modern philosophy offers several plausible theories for accepting the results of our epistemic practice: pragmatists suggest we accept objective knowledge as true because it works; some falsificationists suggest we do so because the theory of evolution tells us to trust the mechanisms by which we acquire it; and Wittgenstein would have us do so because of the central role it plays in our form of life [Rescher (1977); Popper (1972); Wittgenstein (1974)]. I do not think that these theories are intended to secure individual facts as certain - they are intended rather to apply to the whole body of knowledge thrown up by our epistemic practice - but even if I am wrong about this, it is easy to see how they could be made to apply to a body of knowledge. Any one of them, therefore, could provide a suitable response to Derrida's scepticism and anti-rationalism. Derrida does not try to counter them because he thinks his attack on all fixed signifieds undermines them as it does Husserl's faith in a metaphysics of presence. Yet I have argued that signifieds can be fixed by an appropriate theoretical context, and this means that theoretical justifications of our epistemic practice do not fail along with the idea of truth as absolute certainty. The fact is that the unwarranted leap in Derrida's theory of meaning also undermines his sceptical anti-rationalism. The absence of signifieds fixed independently of their context really does imply there are no brute facts - nothing is present to consciousness as a thing in itself. Thus, Derrida is right to reject Husserl's account of phenomenology as a method of uncovering a priori truths by investigating objects that are present to consciousness as such. However, the existence of signifieds fixed by an appropriate theoretical context implies we can construct facts by our theoretical activity, and this opens up the possibility of a defence of objective knowledge conceived as the product of a social practice. Thus, Derrida is wrong to reject the very idea of objective knowledge for a sceptical anti-rationalism.

\section{RECONSTITUTING PHENOMENOLOGY}


My arguments clearly suggest that we need to re-think the nature of phenomenology in order to free it from the myth of presence. I would like to conclude by looking briefly at how we might do this. The key aspect is to accept that the objects of consciousness are always, in part, theoreticallyconstructed. Throughout I have argued for a relational theory of meaning, and this theory is capable of sustaining Derrida's critique of Husserl's concept of presence. Nothing is simply given to consciousness: every object that appears before consciousness is in part a theoretically-constructed one. Phenomenology, therefore, cannot give us knowledge of objects that are simply given to consciousness. Rather, it must explore objects that are constructed in part by our theoretical activity. To accept this is not necessarily, however, to conclude that a phenomenological concentration on the content of consciousness can provide us only with subjective insights into our individual minds. On the contrary, the conclusions that we derive from our phenomenological investigations will be valid for all those who construct objects with the aid of the same theories we use. We can still accept, therefore, much of Husserl's position: we can accept that phenomenology begins with a rigorous inspection of one's own consciousness and intellectual processes; we can accept that in performing this inspection, philosophers exclude all assumptions about the external causes and consequences of these processes; and we can accept that this inspection leads not to subjective knowledge but to a grasp of ideas or meanings common to several minds. What we cannot accept is his claim that these ideas or meanings are common to every mind. We have to regard them instead as common to any mind that shares our theoretical assumptions. Phenomenology does not give us certain a priori knowledge. Instead, it provides us with knowledge that will be taken as true by all those who share our particular form of life.

I deliberately used the phrase "form of life" here because I want to highlight the extent to which adopting a relational theory of meaning - rejecting Husserl's myth of presence - might lead us to rethink phenomenology along lines made familiar by Wittgenstein [Wittgenstein (1972)]. Certainly there are significant parallels between my brief account of phenomenology as the study of a consciousness composed of objects that are fixed by our shared acceptance of certain theories, and Wittgenstein's account of philosophy as the study of the nature and use of our shared language. Firstly, both accept, with Derrida, that there are no brute facts, so if stable meanings and truth exist, they must do so within the context of a body of theories or language. Moreover, both assert, against Derrida, that the relevant body of theories or language really does provide us with stable meanings, and thus a basis from which to defend an account of objective knowledge as a product of a comparison between rival bodies of theories. Finally, both a reconstituted phenomenology and Wittgenstein therefore face 
the question of what reason we can have for taking the knowledge generated by our epistemic practice to be true. Wittgenstein, of course, tries to find such a reason in the relationship that we have to our form of life, and I think this is indeed the best way to proceed. Nonetheless, phenomenologists might perhaps choose simply to bracket-off the question of why we should accept the theories that we do, in much the same way as Husserl brackets-off the question of the relationship of the objects that appear before consciousness to an external reality.

Although there are similarities between my account of a reconstituted phenomenology and Wittgenstein's approach to philosophy, there are also important differences between them. In particular, my reconstituted phenomenology goes to work on concepts and theories, rather than language and its uses. Moreover, I think that this focus on concepts and theories enables us to avoid some problems associated with ordinary language philosophy. Various ambiguities in Wittgenstein's later work have encouraged some of his followers to adopt an extreme linguistic approach to philosophy. There are moments when he seems to argue that philosophy is a study of words, rather than concepts: philosophy, he implies, tells us about how we use words in our ordinary language, not about how we should theorise the world; and it aims to unravel the intellectual confusions created by the bewitching effects of language, not to extend our theoretical understanding of the world [Wittgenstein (1972), $\S 43 \& 126]^{2}$. The reconstituted phenomenology I am advocating, in contrast, makes it quite clear that philosophy goes to work on our concepts so as to improve our theoretical understanding of the world. Firstly, my reconstituted phenomenology would deal emphatically with the way things are, rather than the way we use language; it would explore our concepts in relation to our theories about the world, rather than in relation to the way we deploy them in our language. Whereas extreme linguistic philosophers can appear to be studying words as they are used in ordinary language, a reconstituted phenomenology would look at the theoretically-constructed objects that appear before consciousness. No doubt phenomenologists might still examine ordinary language as a way of exploring these objects; after all, the theories we use to construct these objects will be ones embedded within a language. When they do so, however, they will clearly be discussing questions of linguistic usage only in order to discover things about the concepts, or objects, that appear before consciousness; their concern will remain the concepts and theories that constitute our understanding of the world. A reconstituted phenomenology, in other words, would focus less on using standard forms of speech to clarify actual norms of usage than on evoking unusual situations to clarify our grasp of the limiting cases to which we would apply various concepts and theories. 
In addition, therefore, the principal aim of my reconstituted phenomenology would be to enhance our understanding of the world, rather than to exhibit to us the bewitching effects of language; it would try to derive further theories about the world from our existing ones, rather than to remind us of how we normally use words. Here extreme linguistic philosophers sometimes imply that all philosophical problems arise when philosophers place words in contexts other than those they occupy in ordinary language: because the words do not belong in these contexts, they do not have any true meaning therein, and this absence of true meaning generates apparent paradoxes. Thus, they continue, linguistic philosophy dissolves philosophical problems simply by revealing them to be pseudo-problems that arise when we fail to grasp properly the way ordinary language operates. Philosophers, they conclude, should not develop theories, but rather remind us of how ordinary language operates so as to stop us worrying about meaningless paradoxes. In contrast, a reconstituted phenomenology would explore the theoreticallyconstructed objects that appear before consciousness in order to reach a better understanding of their nature; it would explore our current understanding of the world so as to make our concepts clearer and then use them to develop further theories about the world. Because the theoretically-constructed objects of consciousness constitute our understanding of the world, we can deepen and extend this understanding by exploring both their nature and their relationship to one another. This is what a reconstituted phenomenology would seek to do. In many ways, of course, it is also what Wittgenstein tries to do: certainly the philosophical problems he considers rarely resemble cases in which we use one word when we should have used another - they are more like cases in which we know which words to use but are confused about the concepts we apply; and the resolutions he provides to these problems rarely consist of clarifications of the way we use language - they are more like explorations of the limitations of theoretical models of the world suggested to us by our language. What I have tried to do, therefore, is to bring phenomenology and Wittgenstein's approach to philosophy closer to one another. I have tried to do so by freeing phenomenology from Husserl's myth of presence and by suggesting that we see Wittgenstein as interested in concepts and theories rather than words and their uses.

Department of Politics, University of Newcastle

Newcastle upon Tyne NE1 7RUUK

E-mail:Mark.Bevir@ncl.ac.uk 
${ }^{1}$ Saussure called on linguists to focus exclusively on langue because doing so would enable them to develop a science, not because he denied we could have access to stable meanings. He explained: "in separating language from speaking we are at the same time separating (1) what is social from what is individual; and (2) what is essential from what is accessory" (14).

${ }^{2}$ Not all ordinary language philosophy exhibits these problems; much of Wittgenstein's work, and also that of many of his followers conveys a view of philosophy very close to my account of a reconstituted phenomenology (Newell).

\section{REFERENCES}

Bevir, M. (1994), "Objectivity in History", History and Theory, vol. 33, pp. 328-44.

Derrida, J. (1973), Speech and Phenomena, and Other Essays on Husserl's Theory of Signs, trans. D. Allison, Evanston, Ill., Northwestern University Press.

- (1977), Of Grammatology, trans. G. Spivak, Baltimore, John Hopkins University Press.

-(1978a), Edmund Husserl's "Origin of Geometry": An Introduction, trans. J. Leavey Jr., New York, Nicolas Hays.

-(1978b), Writing and Difference, trans. A. Bass, London, Routledge \& Kegan Paul.

- (1982), Margins of Philosophy, trans. A. Bass, Brighton, Eng., Harvester Press.

Husserl, E. (1931), Ideas: General Introduction to Pure Phenomenology, trans. W. Gibson, London, George Allen \& Unwin.

- (1978), The Origin of Geometry, published as an appendix to Derrida (1978a).

Newell, R. (1967), The Concept of Philosophy, London, Methuen.

POPPER, K. (1972), Objective Knowledge: An Evolutionary Approach, Oxford, Clarendon Press.

Rescher, N. (1977), Methodological Pragmatism, Oxford, Basil Blackwell.

Saussure, F. DE, (1966), Course in General Linguistics, ed. C. Bally \& A. Sechehaye, trans. W. Baskin, New York, McGraw-Hill.

Wittgenstein, L. (1972), Philosophical Investigations, trans. G. Anscombe, Oxford, Basil Blackwell.

-(1974), On Certainty, trans. D. Paul \& G. Anscombe, Oxford, Basil Blackwell. 